\title{
UTILIZAÇ̃̃O DOS DADOS DE ATENDIMENTOS DO CORPO DE BOMBEIROS PARA REDUÇÃO DE ACIDENTES DE TRÂNSITO
}

\author{
USE OF FIRE FACILITY TESTS FOR THE REDUCTION OF TRANSIT ACCIDENTS
}

\author{
Amarildo Roberto Ribeiro ${ }^{1}$
}

\begin{abstract}
Resumo
Os Acidentes de Trânsito tornaram-se um dos maiores problemas de saúde pública no mundo. No Brasil anualmente ceifa a vida de aproximadamente 37 mil pessoas, sendo que outras milhares tem suas vidas e atividades modificadas por esse tipo de sinistro, podendo ser evitado por meio de campanhas de sensibilização, mudança de comportamento do condutor, fiscalização constante e mudanças na estrutura viária de ruas e estradas. Cascavel possui, desde 2010, o Comitê Intersetorial de Prevenção e Controle de Acidente de Trânsito do Município de Cascavel (COTRANS) que realiza ações em consonância com o Projeto Vida no Trânsito (PVT) do Ministério de Saúde. Esse trabalho tem por objetivo mostrar a importância da utilização de dados de atendimentos de acidentes de trânsito realizados pelo Corpo de Bombeiros para a mitigação de fatores e condutas de risco, que geram tais sinistros, bem como, propor ações para diminuição desses acidentes e suas consequências.
\end{abstract}

Palavras-chave: Óbitos. Dados. Articulação. Sistema. Bombeiro

\begin{abstract}
Traffic Accidents have become the biggest public health problems in the world. In Brazil, life in general is synonymous with synergism, and changes are modified through synergies and synergies. road and roads. Cascavel has, since 2010, the Committee for Prevention and Control of Traffic Accidents of the Municipality of Cascavel (COTRANS) that carries out actions in consonance with the Life in Transit Project (PVT) of the Ministry of Health. This work temponent for use the use of the risk factors, which generate such claims, as well as propose actions to reduce the respective probabilities and their consequences..
\end{abstract}

Key words: Deaths. Data. Articulation. System. Firefighter

\footnotetext{
${ }^{1}$ Corpo de Bombeiros do Paraná, Major do Corpo de Bombeiros, Tecnólogo em Processamento de Dados e Especialista em Prevenção Contra Incêndio, amarildobomber@gmail.com
} 


\section{INTRODUÇÃO}

Os acidentes de trânsito no Brasil representam um grave problema para a sociedade, gerando custos econômicos e sociais altíssimos. Estudos realizados apontam que no país aproximadamente 37 mil pessoas morrem todos os anos em virtude desses acidentes, gerando um custo médio hospitalar em torno de 90 mil reais por acidente com vítima, isso sem contar o custo social traumático das famílias que perdem seus entes em função desse tipo de sinistro.

No Brasil, os acidentes de trânsito representam a primeira causa de morte na faixa de 15 a 29 anos de idade; a segunda, na faixa de 5 a 14 anos; e a terceira, na faixa de 30 a 44 anos, e se nada for feito continuaremos a perder muitos jovens precocemente em função de sinistros que podem ser evitados.

Diante da problemática mundial gerada pelos acidentes de trânsito a Organização das Nações Unidas (ONU) decretou em 2010 a Década Mundial de Ações para a Segurança Viária (2011-2020), coordenada pela Organização Mundial da Saúde (OMS), cujo objetivo é estimular ações para reduzir o número de feridos e de óbitos decorrentes da violência no trânsito (OMS, 2013).

Nesse contexto, foi criado pelo Ministério da Saúde o Projeto Vida no Trânsito (PVT), uma iniciativa brasileira voltada para a vigilância e prevenção de lesões e mortes no trânsito e promoção da saúde, em resposta aos desafios da Organização das Nações Unidas (ONU) para a Década de Ações pela Segurança no Trânsito 2011 - 2020 (PVT, 2014).

O PVT trabalha com uma metodologia que institui 6 eixos voltados para ações de diminuição do número de acidentes

- Articulação Intersetorial;

- Qualificação e integração das informações; 
Revista Científica do Corpo de Bombeiros Militar de Pernambuco

XVIII Seminário Nacional de Bombeiros - Foz do Iguaçu PR

Vol.04 No11 - Edição Especial XVIII SENABOM - ISSN 2359-4829

Versão on-line disponível em: http://www.revistaflammae.com.

- Análise de fatores de risco, condutas inadequadas dos usuários do trânsito, fatores contributivos e grupos de vítimas envolvidos no acidente de trânsito;

- Elaboração de um plano de ações integradas e intersetoriais de segurança no trânsito e execução das intervenções intersetoriais e integradas;

- Monitoramento do Projeto;

- Renovação e expansão.

Em Cascavel, com o intuito de diminuir os índices de acidentes houve a implantação do Projeto de Redução da Morbimortalidade por Acidente de Trânsito no município em 2010, sendo o projeto aceito pelo Ministério da Saúde para estruturação de ações de prevenção de acidentes de trânsito. Dentre as ações deste projeto foi instituído o Comitê Intersetorial de Prevenção e Controle de Acidente de Trânsito do Município de Cascavel (COTRANS) por meio do Decreto Municipal no 9772/2011.

O Cotrans tem a participação de várias instituições da sociedade civil organizada, que tem ligação com o tema Acidente de Trânsito, sendo elas: Secretaria Municipal de Saúde (Epidemiologia); 10 Regional de Saúde, Secretaria Municipal de Educação; Secretária Municipal de Administração, Companhia de Trânsito de Cascavel (CETTRANS), Corpo de Bombeiros/SIATe, Polícia Militar, Polícia Rodoviária Federal, Polícia Rodoviária Estadual, Universidades (UNIOESTE, UNIPAR, FAG e UNIVEL), CONSAMU, Unidades de Saúde (Hospital Universitário, Policlínica, São Lucas e UPA's), Concessionárias (Ecocataratas e Viapar), SINDETAXI, Conselho de Segurança (CONSEG), Sindicato de Empresas de Seguros e Sindicato das Auto-escolas.

O Cotrans tem por objetivos: Identificar os principais fatores que geram acidentes de trânsito; Propor ações preventivas; Realizar campanhas e ações educativas e preventivas; e, Sensibilizar a população quanto ao problema do acidente de trânsito.

Com a instituição do COTRANS foi possível ampliar um trabalho intersetorial voltado a prevenção de acidentes de trânsito no município, com planejamento de ações educativas integradas, realização de seminários, audiências públicas entre outras ações, trazendo assim a problemática dos acidentes de trânsito para discussão com a sociedade. 
Revista Científica do Corpo de Bombeiros Militar de Pernambuco

XVIII Seminário Nacional de Bombeiros - Foz do Iguaçu PR

Vol.04 No11 - Edição Especial XVIII SENABOM - ISSN 2359-4829

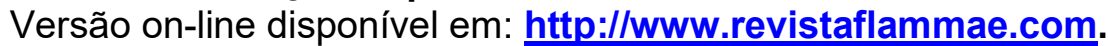

Com objetivo de identificar o perfil dos acidentes de trânsito e das vítimas o COTRANS instituiu a Comissão de Análise dos Acidentes (COB), sendo composta por órgãos que atendem os acidentes de trânsito.

Segundo o PVT para realizar o levantamento dos dados é importante à articulação das entidades que possuem as informações de acidentes de trânsito no município. Nesse contexto, a COB levantou as entidades que poderiam ser fonte de informação, sendo identificadas em Cascavel as seguintes:

- Corpo de Bombeiros: dados das vítimas atendidas e veículos envolvidos;

- Polícia Militar, Polícia Rodoviária Estadual e Polícia Rodoviária Federal: dados do Acidente, dados do envolvido e do veículo;

- Secretaria Municipal de Saúde e $10^{\mathrm{a}}$ Regional de Saúde: sistema informatizado de informações sobre óbitos (SIM), contendo dados da vítima.

Para a análise dos óbitos a Comissão utiliza uma planilha (Figura 1 - repassada pelo PVT) onde são inseridos os dados das vítimas sendo pontuados os Fatores de Risco e Condutas de Risco com escores (10/8/6/4/2/0), do maior para o de menor importância e Conduta do Usuário (5/3/1) também do maior para o menor.

Nesta planilha são analisados diversos elementos como:

- Fatores de Risco: velocidade, álcool, infraestrutura, veículo, fadiga, visibilidade, drogras, celulares.

- Condutas de Risco: avanço de sinal, condutor sem habilitação, transitar em local proibido, transitar em local impróprio, mudança de faixa/pista sem sinalização prévia, desrespeitar distância mínima entre veículos, converter/cruzar sem dar preferência, não dar preferência pedestre na faixa, falta de atenção.

- Condutas do Usuário que Agravam as Lesões: ausência do cinto de segurança, veículo sem "crash protetion", fatores pré-hospitalares, objetos laterais a via, ausência do capacete. 
Revista Científica do Corpo de Bombeiros Militar de Pernambuco

XVIII Seminário Nacional de Bombeiros - Foz do Iguaçu PR

Vol.04 N011 - Edição Especial XVIII SENABOM - ISSN 2359-4829

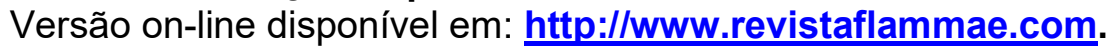

Com base nessa planilha os membros da Comissão analisam individualmente cada sinistro para concluir as causas e fatores que levaram ao acidente e ao óbito das vítimas envolvidas.

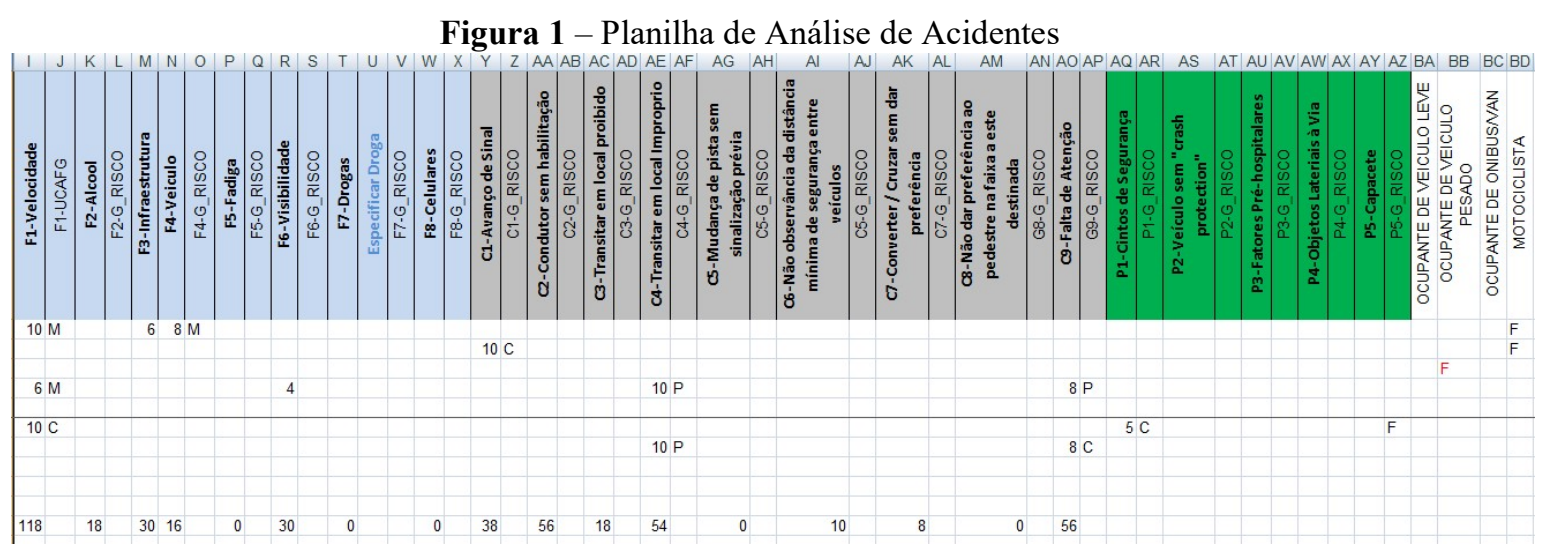

Fonte: PVT Cascavel (2016)

O objetivo desse artigo é mostrar a importância da utilização de dados de atendimentos de acidentes de trânsito realizados pelo Corpo de Bombeiros para a mitigação de fatores e condutas de risco, que geram tais sinistros, bem como, propor ações para diminuição desses acidentes e suas consequências.

\section{DESENVOLVIMENTO}

\section{Materiais e Métodos:}

Para se atingir os objetivo propostos utilizou-se de um estudo descritivo sobre perfil dos acidentes de trânsito ocorridos no município de Cascavel/PR, no ano de 2017, destacando as variáveis sexo, idade, tipo de vítima (pedestre, ciclista, motociclista, ocupante de veículos), local do óbito (perímetro urbano, rodovias federais e estaduais de abrangência do município e instituições de saúde municipais), principais causas e dias de maior número de acidentes.

A fonte de dados foi o COTRANS, por meio da Comissão de Análise de Acidentes que analisou óbitos do ano de 2017 com base na declaração de óbito (DO), nos registros do Corpo de Bombeiros, Boletim de Acidente de Trânsito das Polícias 
Revista Científica do Corpo de Bombeiros Militar de Pernambuco

XVIII Seminário Nacional de Bombeiros - Foz do Iguaçu PR

Vol.04 No11 - Edição Especial XVIII SENABOM - ISSN 2359-4829

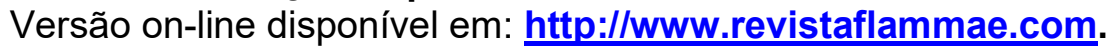

Militar, Polícia Rodoviária Federal, Polícia Rodoviária Estadual, e informações não oficiais de órgãos de imprensa.

A partir da planilha de análise de acidentes sistematizada pela Comissão de Análise de Acidentes as informações foram lançadas em gráficos e tabelas, posteriormente, com tais dados foi possível verificar quais os fatores e condutas de risco responsáveis pelos acidentes, e, finalmente, sugerir ações coordenadas para mitigação dos acidentes e suas consequências.

\section{Dados de Atendimentos do Corpo de Bombeiros:}

O Corpo de Bombeiros da Polícia Militar do Paraná (CB-PMPR), desde 2005, utiliza um sistema informatizado batizado de Sistema de Registro de Ocorrências e Estatísticas do Corpo de Bombeiros - SYSBM, onde são cadastradas todas as informações decorrentes dos atendimentos realizados.

Dentre os atendimentos realizados pela corporação, destaca-se o atendimento de acidentes de trânsito, que representam quase metade de todos os atendimentos realizados pelo CB-PMPR, necessitando que medidas preventivas sejam implementadas por todos os órgãos que atendem tal natureza de ocorrência.

Neste contexto, o PVT visa implementar uma Articulação Intersetorial através da parceria entre os órgãos que atendem acidentes de trânsito, na busca ações integradas para mitigação desses sinistros: criação de "lista única"; base de dados com todas as informações de acidentes; análise dos dados; avaliação de condutas e fatores de risco; verificação de locais e horários de maior incidência; sugestão de políticas públicas na área de educação, fiscalização e engenharia de tráfego; e, integração da sociedade sobre o tema.

O CB-PMPR tem participação de destaque, uma vez que no Paraná, a maioria dos atendimentos de ocorrências de acidente de trânsito com vítima é realizado pela corporação, portanto, possui uma base de dados muito rica em informações, que pode e deve ser utilizada para análise e proposição de ações preventivas. 
Revista Científica do Corpo de Bombeiros Militar de Pernambuco

XVIII Seminário Nacional de Bombeiros - Foz do Iguaçu PR

Vol.04 No11 - Edição Especial XVIII SENABOM - ISSN 2359-4829

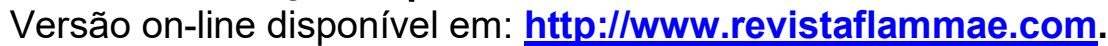

Visando subsidiar o PVT com informações sobre Acidentes de Trânsito e com base no Decreto Estadual que instituiu o Comitê Estadual do PVT, o Corpo de Bombeiros, que é integrante do mesmo, fornece relatório qualitativo, que pode ser exportado para o Excel, com informações dos atendimentos realizados, conforme Figura 2.

Figura 2 - Relatório de Acidentes de Trânsito

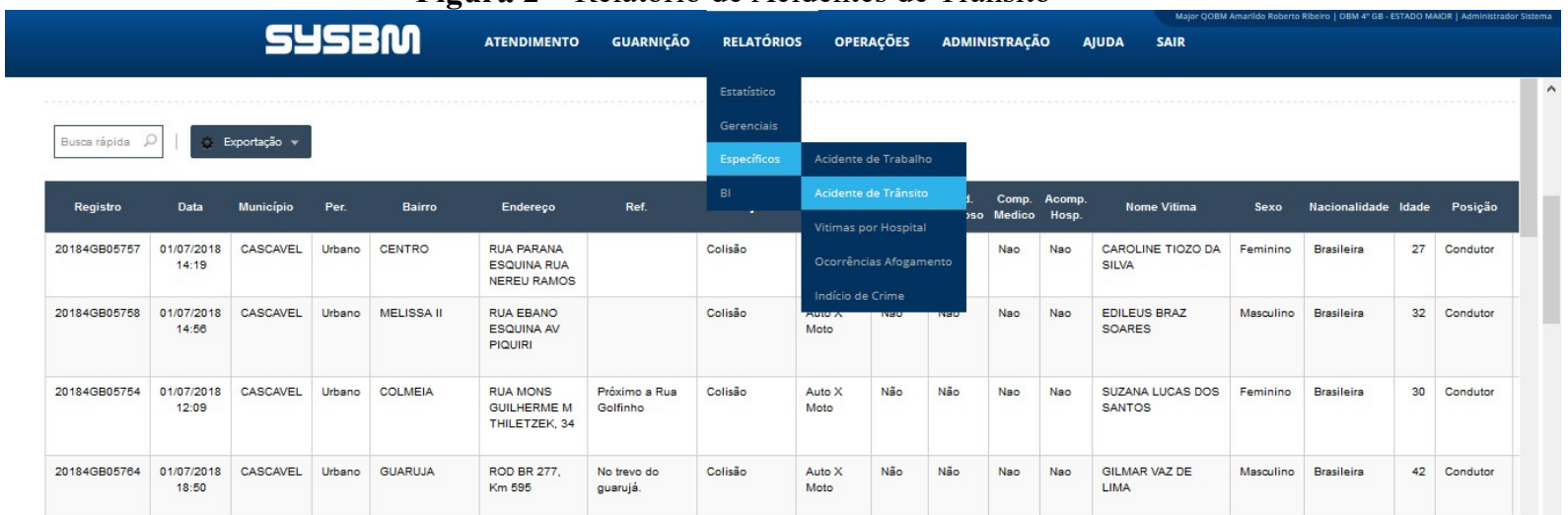

Fonte: SYSBM (2018)

Neste relatório de acidentes são apresentados dados do sinistro, imprescindíveis para uma análise das condições em que o sinistro, tais como:

- Dados do local: data, hora, endereço, bairro, referência, georreferência, natureza da ocorrência;

- Dados da vítima: nome, idade, sexo, condição de segurança, posição no veículo, viatura de transporte, hospital de destino;

- Dados do veículo: marca, modelo, ano, placa, condutor, proprietário, existência airbag.

O SYSBM (2018) também fornece relatório com georreferenciamento de acidentes atendidos, conforme Figura 3, que se torna uma importante ferramenta para planejamento de ações de intervenção da estrutura viária do município analisado. 
Revista Científica do Corpo de Bombeiros Militar de Pernambuco

XVIII Seminário Nacional de Bombeiros - Foz do Iguaçu PR

Vol.04 No11 - Edição Especial XVIII SENABOM - ISSN 2359-4829

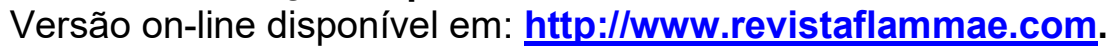

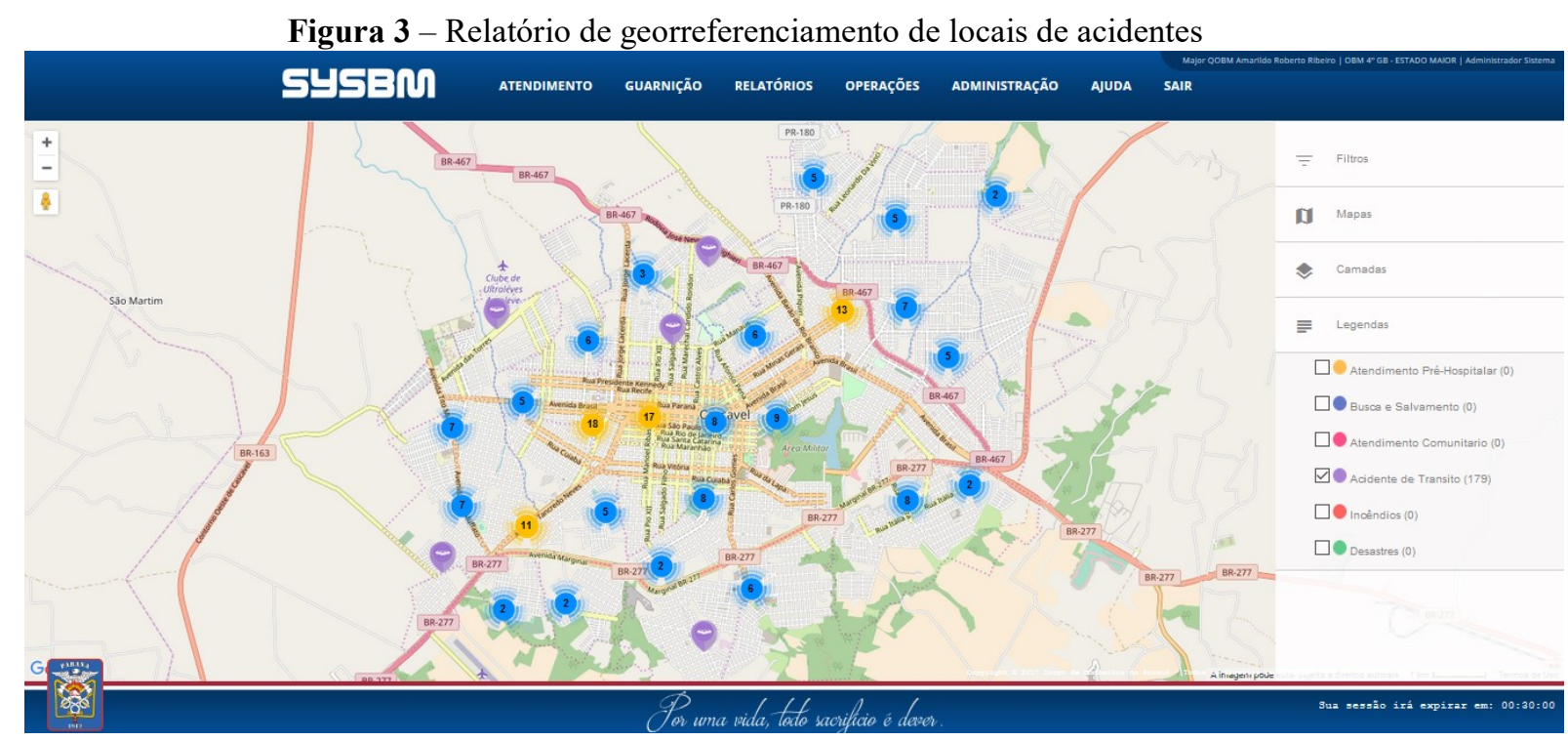

Fonte: SYSBM (2018)

\section{Compilação de dados e análise das informações através da metodologia do PVT:}

Os dados repassados ao PVT juntam-se aos demais dados dos órgãos parceiros: Polícia Militar, Polícia Rodoviária Federal, Polícia Rodoviária Estadual, Secretaria Municipal de Saúde, 10 $0^{\text {a }}$ Regional de Saúde, com tais informações a Comissão de Análise prepara uma lista única, que congrega todas as informações relevantes sobre os acidentes de trânsito ocorridos no município no período analisado. A comissão optou por analisar apenas os casos de óbitos ocorridos devido a grande demanda e o tempo que enseja a análise minuciosa, conforme prevê a metodologia do programa.

$\mathrm{Na}$ análise dos óbitos são lidos os boletins de ocorrência dos órgãos que atenderam o acidente: PRF, PRE, Polícia Militar (conforme o caso), Corpo de Bombeiros, juntam-se ainda as informações do Sistema de Morbimortalidade e matérias jornalísticas que noticiaram o fato. Diante de todos esses dados são pontuadas as causas determinantes na Planilha sugerida pelo PVT, conforme Figura 1, chegando a conclusão dos fatores e condutas de risco que deram causa ao acidente analisado.

De todas as análises realizadas no período, é possível gerar um relatório: trimestral, semestral ou anual, que aponta as principais causas dos acidentes. Com isso é 
Revista Científica do Corpo de Bombeiros Militar de Pernambuco

XVIII Seminário Nacional de Bombeiros - Foz do Iguaçu PR

Vol.04 N011 - Edição Especial XVIII SENABOM - ISSN 2359-4829

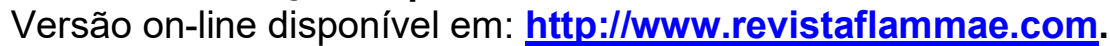

possível identificar os pontos de convergência de condutas e fatores de risco e programar estratégias para mitigação dos mesmos, facilitando muito o planejamento dos órgãos envolvidos.

Para ilustrar melhor a situação em questão, será apresentado a seguir os gráficos gerados, referentes as análises realizadas no ano de $2017 \mathrm{em}$ Cascavel-PR.

As informações a seguir foram obtidas a partir da junção de dados de acidentes atendimentos pelos órgãos: Corpo de Bombeiros, Polícia Militar, Polícia Rodoviária Federal, Polícia Rodoviária Estadual, Companhia de Transporte e Trafego de Cascavel, Secretaria Municipal de Saúde, $10^{\mathrm{a}}$ Regional de Saúde e órgãos de imprensa de Cascavel, e referem-se a 51 óbitos registrados no ano de 2017 no município de Cascavel (área urbana e rodovias).

Na Figura 4 é apresentado o gráfico que indica a localização dos óbitos ocorridos, havendo um destaque para acidentes em rodovia, se sobrepondo aos ocorridos na área urbana, que do ponto de vista de ações pode representar a necessidade de ampliação de fiscalização e orientação nestes locais.

Figura 4 - Gráfico quanto a localização dos acidentes

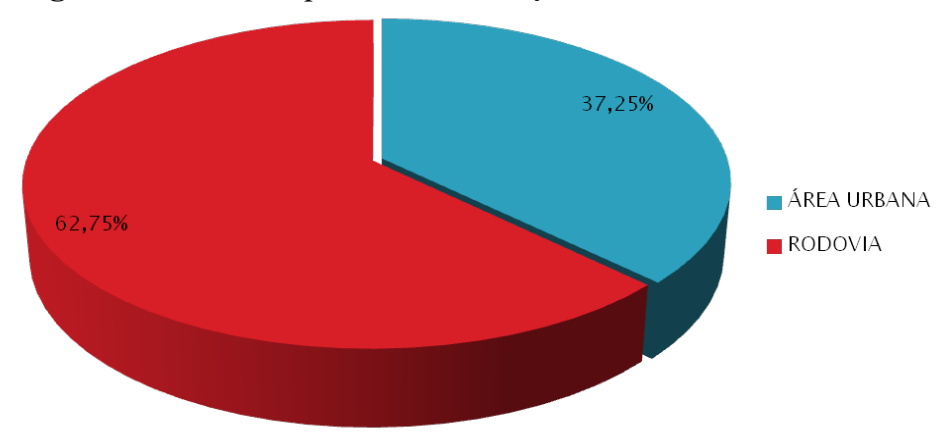

Fonte: PVT Cascavel

Observa-se na Figura 5 o gráfico com as informações quanto a idade das vitimas, onde nota-se que a idade entre 18 a 35 anos prevalece em número de óbitos, ensejando a necessidade de um trabalho mais direcionado para essa faixa etária.

Figura 5 - Gráfico com informações quanto a idade das vítimas 
Revista Científica do Corpo de Bombeiros Militar de Pernambuco

XVIII Seminário Nacional de Bombeiros - Foz do Iguaçu PR

Vol.04 No11 - Edição Especial XVIII SENABOM - ISSN 2359-4829

Versão on-line disponível em: http://www.revistaflammae.com.

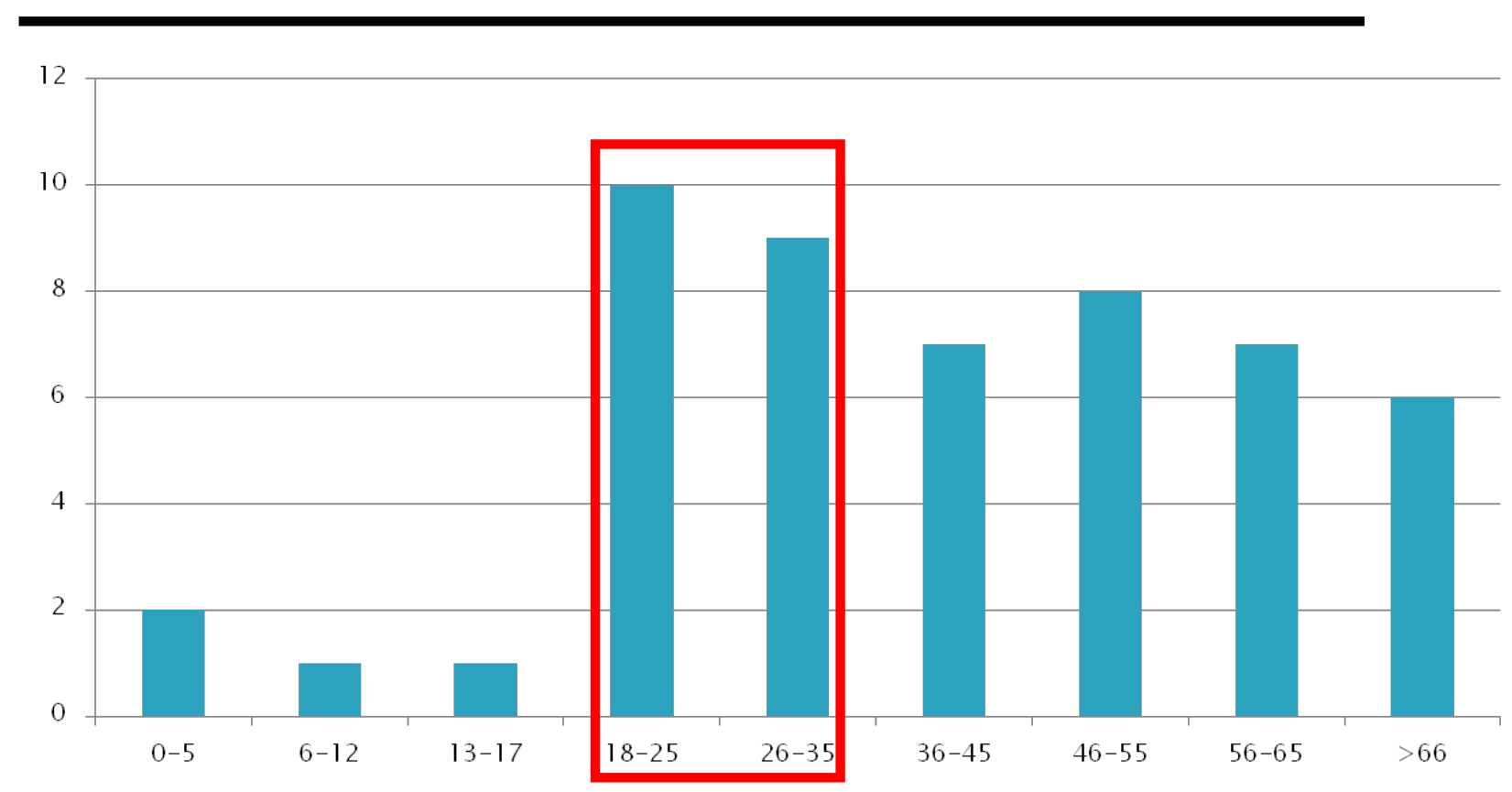

Fonte: PVT Cascavel

Na Figura 6 observa-se que o dia da semana com maior número de óbitos em 2017 foi a terça feira, sendo o período da tarde o de maior quantidade de óbitos. Nas análises observou-se ainda que a maior parte destes óbitos ocorreu em rodovia, ou seja, pessoas que vinham ou retornavam de Cascavel.

Figura 6 - Gráfico com informações quanto dia da semana e período do dia

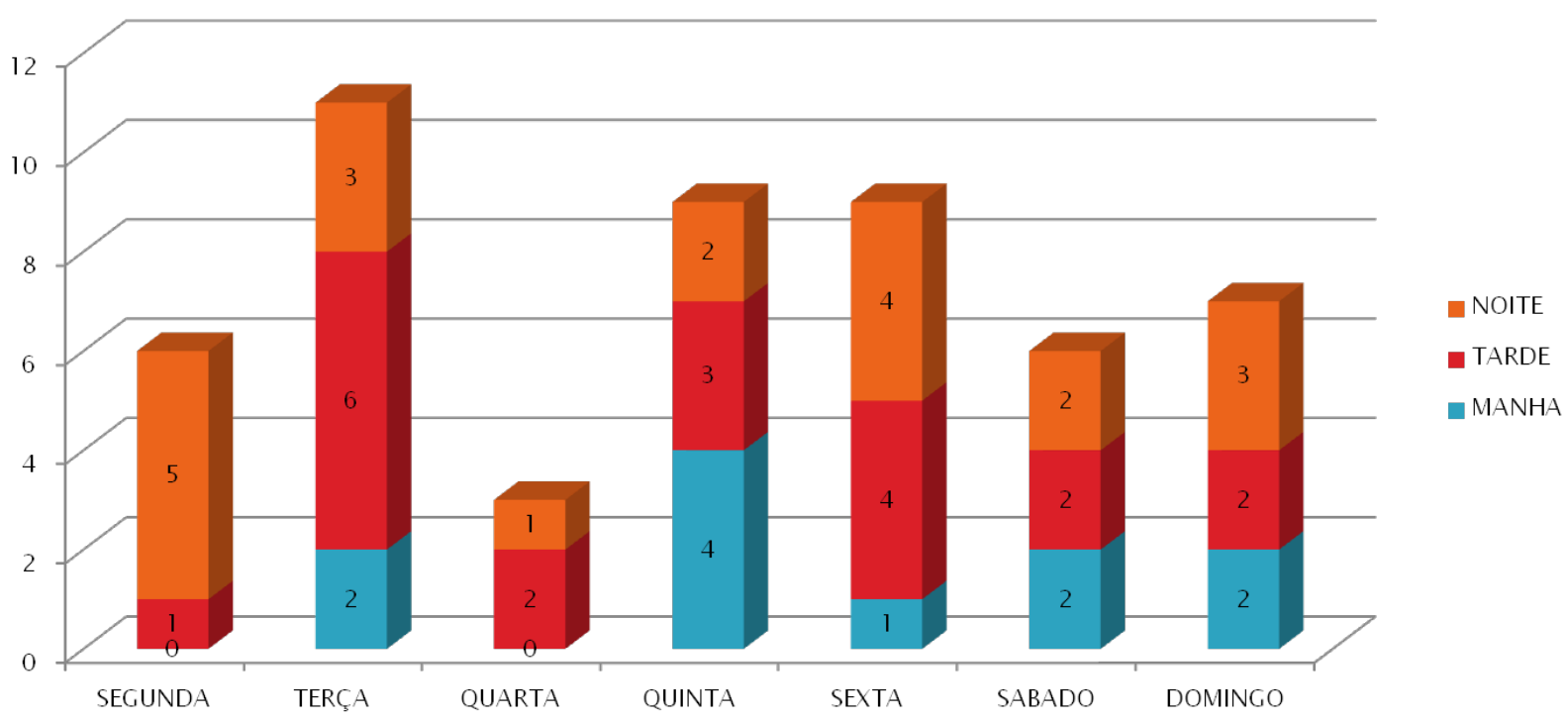

Fonte: PVT Cascavel 
Revista Científica do Corpo de Bombeiros Militar de Pernambuco

XVIII Seminário Nacional de Bombeiros - Foz do Iguaçu PR

Vol.04 No11 - Edição Especial XVIII SENABOM - ISSN 2359-4829

Versão on-line disponível em: http://www.revistaflammae.com.

Abaixo verificamos a Figura 7 é apresentado o gráfico com o gênero das vítimas, ficando em destaque o Masculino, que representa quase $70 \%$ dos óbitos registrados, denotando a necessidade de um trabalho direcionado a esse público.

Figura 7 - Gráfico com informações quanto ao gênero das vítimas

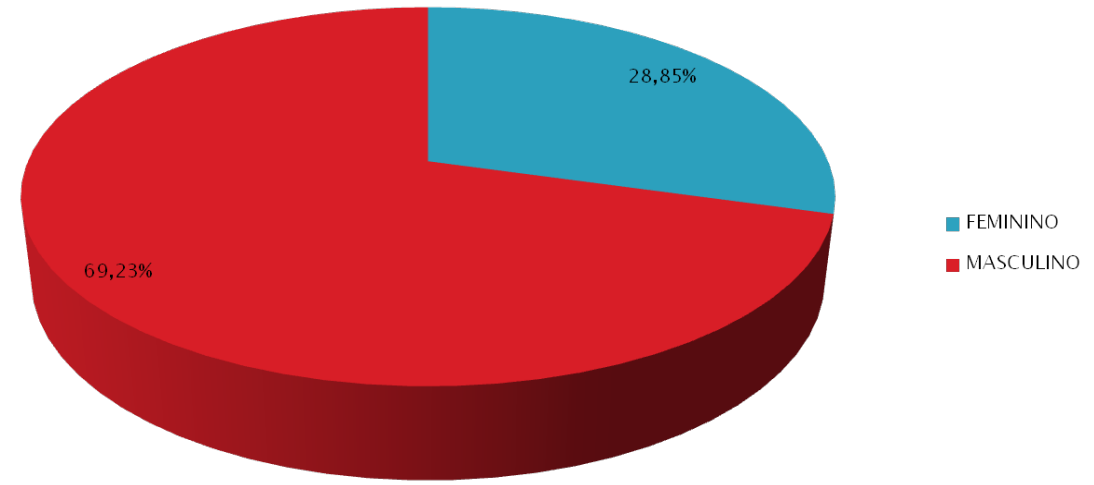

Fonte: PVT Cascavel

Observa-se na Figura 8 que os maiores números de óbitos ocorreram com Motociclistas e Pedestres, seguidos por Ocupantes de Veículos Leves, mostrando exatamente os maiores públicos que precisam ser trabalhos preventivamente.

Figura 8 - Gráfico com informações de óbitos por status da vítima

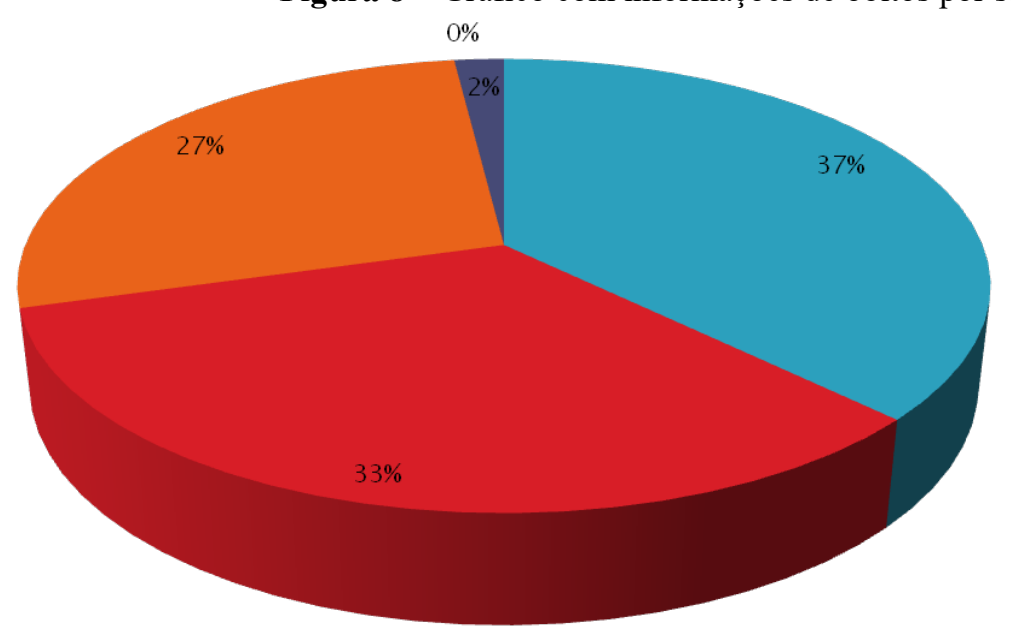

- MOTOCICLISTA

PEDESTRE

- OCUPANTE DE VEÍCULO LEVE

- OCUPANTE DE VÉ́CULO PESADO

- CICLISTA

Fonte: PVT Cascavel 
Revista Científica do Corpo de Bombeiros Militar de Pernambuco

XVIII Seminário Nacional de Bombeiros - Foz do Iguaçu PR

Vol.04 No11 - Edição Especial XVIII SENABOM - ISSN 2359-4829

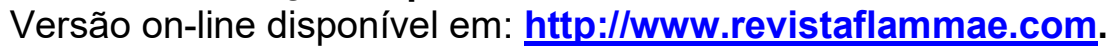

Na Figura 9 verifica-se os principais Fatores e Condutas de Risco dos óbitos registrados em 2017, destacando-se os 3 primeiros: Falta de Atenção, Velocidade e Converter/cruzar sem dar preferência. Em que pese o Fator Álcool não estar nas primeiras colocações, esse fator é sempre subnotificado por falta de informações no local do sinistro. Esses fatores e condutas apurados direcionam as ações preventivas a serem desenvolvidas pelos PVT durante o período subsequente.

Figura 9 - Gráfico com informações de Fatores e Condutas de Risco dos óbitos registrados

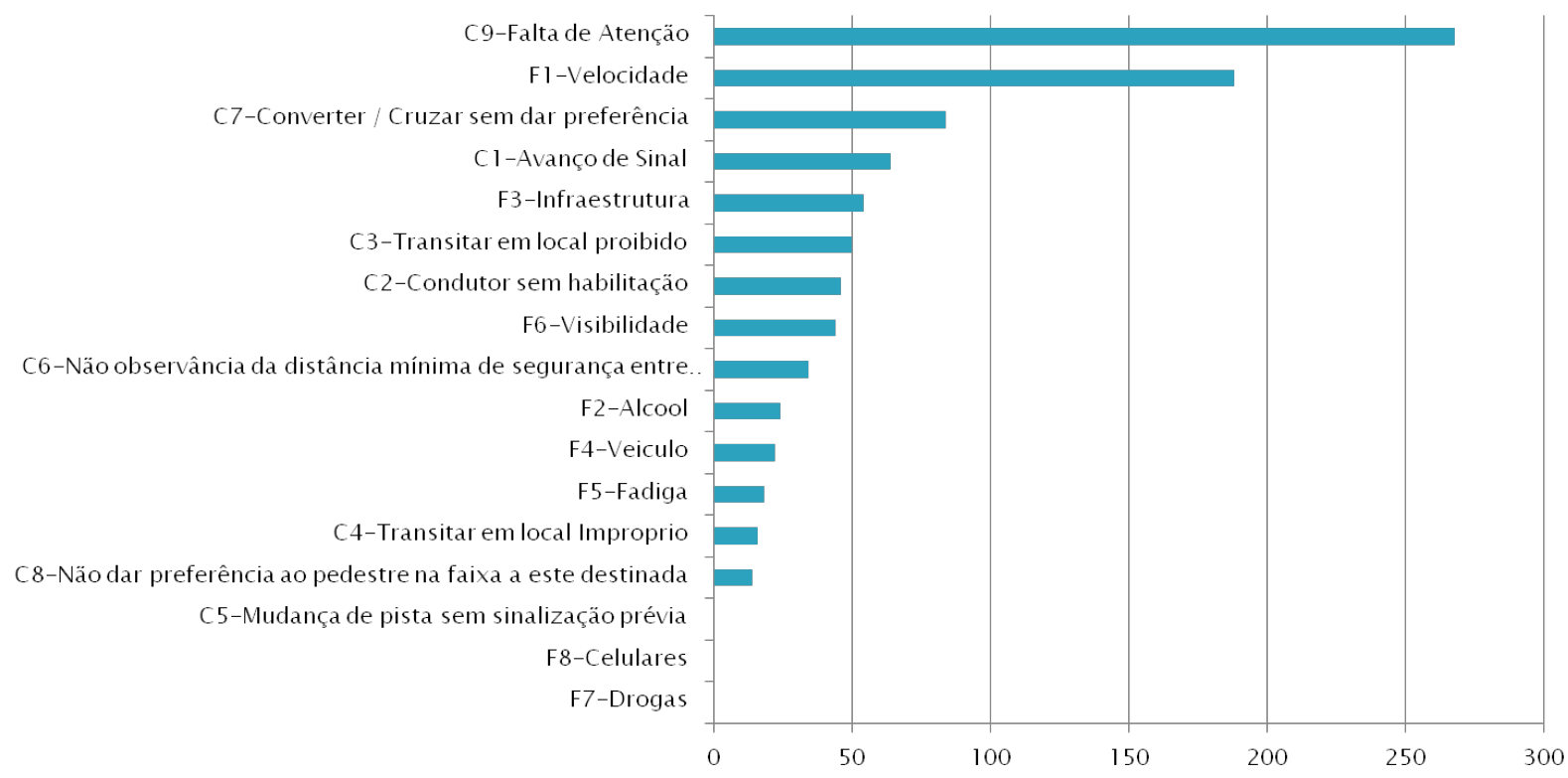

Fonte: PVT Cascavel

A partir dos gráficos obtidos foi possível realizar um planejamento de ações, balizadas pela metodologia do PVT, para enfrentamento dos principais fatores e condutas de risco mapeados durante o estudo.

Dentre as ações de enfrentamento planejadas pelo COTRANS/PVT Cascavel apresenta-se as principais constantes na Tabela 1 a seguir: 
Revista FLAMMAE

Revista Científica do Corpo de Bombeiros Militar de Pernambuco

XVIII Seminário Nacional de Bombeiros - Foz do Iguaçu PR

Vol.04 No11 - Edição Especial XVIII SENABOM - ISSN 2359-4829

Versão on-line disponível em: http://www.revistaflammae.com.

Tabela 1 - Principais ações desenvolvidas pelo PVT para diminuição dos acidentes

\begin{tabular}{|c|c|c|}
\hline Eixo & Ações & Foco \\
\hline \multirow{5}{*}{ Educação } & Palestras em Escolas Estaduais & $\begin{array}{l}\text { Educação de trânsito para } \\
\text { jovens condutores e pedestres }\end{array}$ \\
\hline & $\begin{array}{l}\text { Curso para apenados por crimes de } \\
\text { trânsito }\end{array}$ & $\begin{array}{l}\text { Reeducação para pessoas que } \\
\text { cometeram crimes de trânsito } \\
\text { (álcool) }\end{array}$ \\
\hline & $\begin{array}{l}\text { Blitz educativa no dia do } \\
\text { motociclista }\end{array}$ & Reeducação para motociclistas \\
\hline & Blitz educativa em bares & $\begin{array}{l}\text { Reeducação de condutores } \\
\text { quanto ao consumo consciente } \\
\text { de álcool }\end{array}$ \\
\hline & Pé na faixa & $\begin{array}{l}\text { Educação para pedestres e } \\
\text { condutores sobre a utilização da } \\
\text { faixa de pedestres }\end{array}$ \\
\hline \multirow{3}{*}{ Fiscalização } & Blitz nas rodovias & $\begin{array}{l}\text { Fiscalização de condutores } \\
\text { quanto a estado do veículo, } \\
\text { velocidade e CNH }\end{array}$ \\
\hline & Operação balada segura & $\begin{array}{l}\text { Fiscalização quanto a motoristas } \\
\text { alcoolizados }\end{array}$ \\
\hline & Operação radar & $\begin{array}{l}\begin{array}{l}\text { Fiscalização } \\
\text { velocidade }\end{array} \\
\end{array}$ \\
\hline \multirow{2}{*}{ Infraestrutura } & Sinalização & $\begin{array}{l}\text { Operação de melhoria da } \\
\text { sinalização viária }\end{array}$ \\
\hline & Pontos de maior risco & $\begin{array}{l}\text { Estudo com base nas } \\
\text { informações georreferenciadas } \\
\text { de acidentes dos locais com } \\
\text { maior incidência }\end{array}$ \\
\hline
\end{tabular}

Fonte: PVT Cascavel compilado pelo Autor

Conforme se verifica na Tabela 1, é grande o número de ações desenvolvidas pelo COTRANS/PVT, através de ações articuladas e coordenadas entre os vários órgãos e entidades participantes do Comitê, que objetivam diminuir o número de acidentes de trânsito, que devem ser balizadas por um planejamento bem fundamentado num diagnóstico preciso, que somente foi possível através de dados consistentes.

Na Figura 10 é apresentada a evolução da população, frota de veículos e número de óbitos por acidente de trânsito no município de Cascavel, mostrando que se ainda 
Revista Científica do Corpo de Bombeiros Militar de Pernambuco

XVIII Seminário Nacional de Bombeiros - Foz do Iguaçu PR

Vol.04 N011 - Edição Especial XVIII SENABOM - ISSN 2359-4829

Versão on-line disponível em: http://www.revistaflammae.com.

não foram atingidos os objetivos, nota-se uma mudança positiva, com a queda dos óbitos mesmo com aumento da população e frota de veículos.

Figura 10 - Gráfico com evolução da População X Frota de veículos X Óbitos

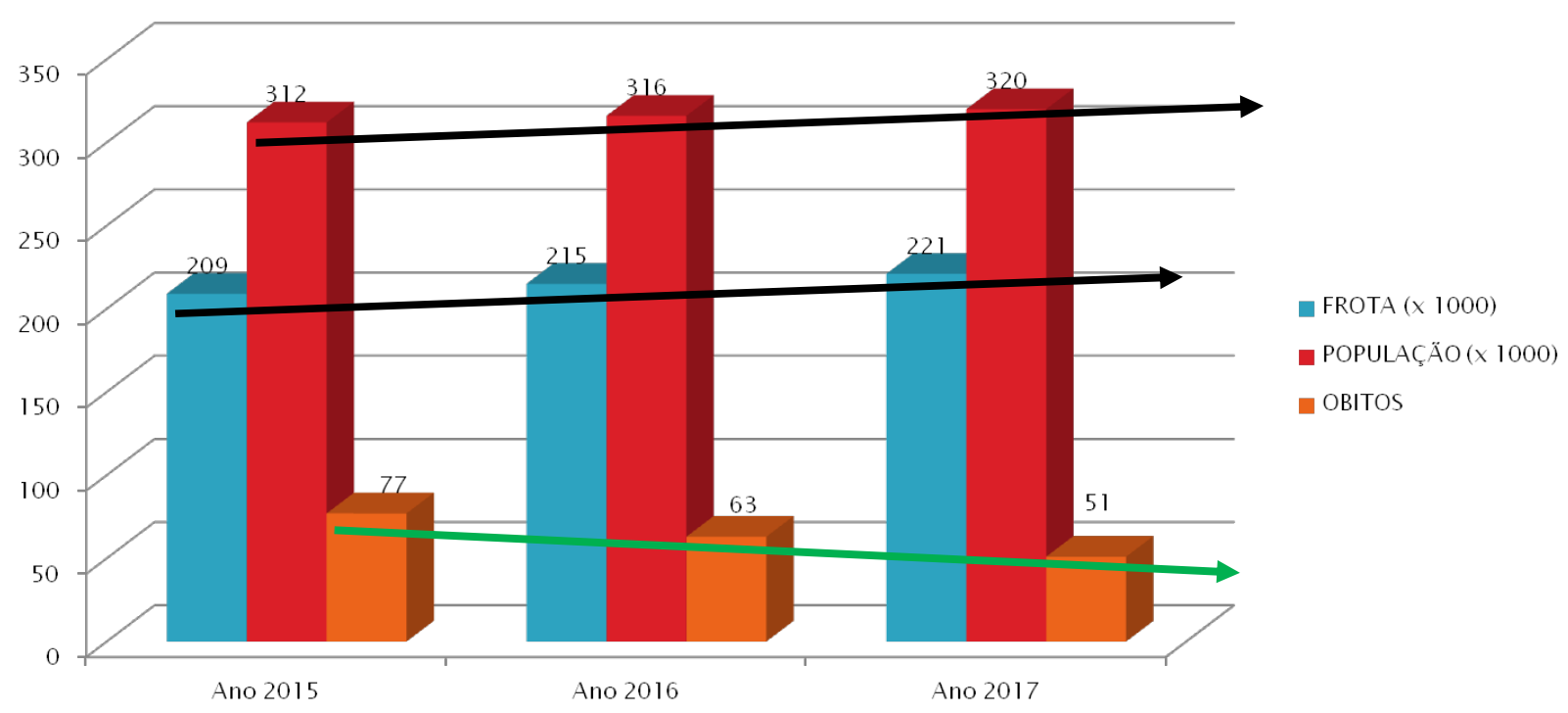

Fonte: PVT Cascavel

Na comparação entre os anos de 2015 a 2017 houve uma diminuição de 34\% no número de óbitos registrados, mesmo com aumento de quase $10 \%$ na população e na frota de veículos do município.

Também na comparação entre 2015 e 2017, seguindo a metodologia do PVT a taxa de óbitos caiu de 24,61 óbitos/100.000hab. para 16,26 óbitos /100.000 hab., portanto, se ainda não se pode comemorar os resultados, pode-se entender que o trabalho realizado está surtindo um efeito positivo, graças ao trabalho contínuo e coordenado.

\section{CONCLUSÕES}

Este artigo apresenta a importância da utilização dos dados de atendimentos de Acidentes de Trânsito realizados pelo Corpo de Bombeiros para a diminuição de óbitos e seus agravos. 
Com o estudo realizado, tendo como base, a análise dos óbitos utilizando-se da metodologia indicada pelo Projeto Vida no Trânsito do Ministério da Saúde, obteve-se várias conclusões relacionadas às causas e fatores principais determinantes para os acidentes, e com isso, possibilitando realizar um trabalho preventivo mais focado nas reais causas dos acidentes.

Verifica-se ainda, que Cascavel, assim como muitas outras grandes cidades, sofre os mesmos problemas relacionados ao trânsito, tais como: imprudência de muitos condutores, excesso de velocidade, conduzir veículo sem estar habilitado, condução sob efeito de álcool, entre outros.

Vimos também que a maior parte dos envolvidos são jovens do sexo masculino, principalmente motociclistas, indicando que campanhas para esses públicos específicos devem ser ampliadas.

Observa-se ainda, que Cascavel, por meio do COTRANS/PVT, já realiza muitas das ações mitigadoras para diminuição dos acidentes (palestras, blitz, ações educativas, orientação para mudanças na infraestrutura viária), porém é necessário continuar e ampliar esse trabalho.

É notório também que o Corpo de Bombeiros, por ser a instituição no município de Cascavel, que mais atende ocorrências de acidente de trânsito com vítimas, tem informações muito importantes sobre esses sinistros e vítimas atendidas, que precisam ser juntadas aos demais órgãos participantes do PVT, para que o estudo desses casos surta os efeitos desejados, principalmente a diminuição dos óbitos dos acidentes de trânsito e suas consequências, estando a corporação trabalhando preventivamente para preservação de vidas, bem mais precioso que enseja a nossa existência.

\section{REFERÊNCIAS}

BRASIL. Ministério da Saúde. Acidentes de transporte terrestre no Brasil: mortalidade, internação hospitalar e fatores de risco no período de 2002 a 2012. Saúde Brasil. 2012. 
Revista Científica do Corpo de Bombeiros Militar de Pernambuco XVIII Seminário Nacional de Bombeiros - Foz do Iguaçu PR

Vol.04 No11 - Edição Especial XVIII SENABOM - ISSN 2359-4829

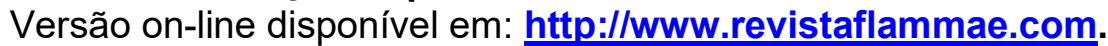

COTRANS. Comitê Intersetorial de Prevenção e Controle de Acidente Trânsito no Município de Cascavel. Cascavel, PR, 2017.

IBGE. Instituto Brasileiro de Geografia e Estatística. Disponível em: <

$\mathrm{http}: / /$ cidades.ibge.gov.br/xtras/perfil.php?lang=\&codmun=410480\&search=parana|c ascavel> Acessado em 04 jul 2017.

IPEA. Instituto de Pesquisa Econômica Aplicada. Impactos Sociais e econômicos dos Acidentes de Trânsito nas Rodovias Brasileiras. Brasília: Ipea; 2006.

MORAES NETO, O.L. et al. . Mortalidade por acidentes de transporte terrestre no Brasil na última década: tendência e aglomeração de risco. Ciências Saúde Coletiva, Rio de Janeiro, v. 17, n. 9, p. 2223-2236, set. 2012.

OPAS, Sistemas de dados: um manual de segurança viária para gestores e profissionais da área. Brasília, D.F., 2012.

PVT. Projeto vida no trânsito. Ministério da Saúde, 2014. Disponível em: $<$ http://portalsaude.saude.gov.br/index.php/o-ministerio/principal/leia-mais-oministerio/711-secretaria-svs/vigilancia-de-a-a-z/violencia-e-acidentes/11512projeto-vida-no-transito> Acessado em 02 jul 2017.

SYSBM. Sistema de Registro de Ocorrências e Estatística do Corpo de Bombeiros. Disponível em:

$<$ http://www.bombeiroscascavel.com.br/registroccb/imprensa.php> Acessado em 02 jul 2018.

UNGARETI, Marly. Perfil dos Acidentes de Trânsito no Município de CascavelPR. Cascavel, 2016. 